\title{
Five Challenges for Benefits Management in Complex Digitalisation Efforts - and a Research Agenda to Address Current Shortcomings
}

\author{
Kirsti Askedal ${ }^{1}$, Leif Skiftenes Flak $^{1}$ and Margunn Aanestad ${ }^{1,2}$ \\ ${ }^{1}$ University of Agder, Norway \\ ${ }^{2}$ University of Oslo, Norway \\ Kirsti.Askedal@uia.no \\ Leif.Flak@uia.no \\ Margunn.Aanestad@uia.no \\ DOI: 10.34190/EJEG.17.2.001
}

\begin{abstract}
Over the past decades a number of benefits realisation (BR) frameworks have been developed. The benefits management model (BMM) is considered to be the most widely adopted and is often seen as a reference for good practice in digitalisation efforts in single organisations. However, this literature provides little support for complex, interorganisational efforts. This is problematic, considering that digitalisation increasingly involves multiple organisations. To explore this gap, we studied the phenomenon in a Norwegian inter-organisational eHealth effort. Based on a qualitative study involving 50 interviews, observations and document analyses, we identify five distinct challenges and suggest a research agenda with five propositions for benefits management in complex digitalisation settings that can be further explored and tested by other researchers. The challenges and propositions constitute novel insights into a poorly understood area and contain implications and directions that can benefit both researchers and practitioners working in similar contexts.
\end{abstract}

Keywords: Benefits realisation, benefits management, inter-organisational digitalisation efforts, societal benefits

\section{Introduction}

Information and Communication Technology (ICT) is a main ingredient in public service innovations that aim to generate societal benefits while supporting underlying public values (Ward and Daniel, 2012; Seemann, Dinesen and Gustafsson, 2013). Digitalisation may drive increased collaboration among organisations in both public and private sectors (Boonstra and de Vries, 2008; Gil-Garcia, 2012; Garmann-Johnsen and Eikebrokk, 2014; van Fenema and Keers, 2018). However, such implementation of digital technologies are not straightforward and organisations struggle to achieve the intended outcome of their investments (Doherty, 2014; Frisk, Bannister and Lindgren, 2015; Mohan, Ahlemann and Braun, 2016; Christensen, 2017; Askedal, 2019). A large proportion of ICT efforts do not deliver expected benefits on time and on budget (Flak, 2012) resulting in loss of profit for private sector and public sector failure to accomplish societal and political goals (Frisk, Bannister and Lindgren, 2015).

Many practical tools and methods have been developed for, and embedded in practice to guide organisations in the process of realising the benefits and increasing the value of ICT-investments (Lin, Pervan and McDermid, 2007; Hellang, Flak and Päivärinta, 2013; Ghildyal, Chang and Joiner, 2018; Burton-Jones and Volkoff, Forthcoming). A stream of research, the benefits realisation (BR) literature has evolved since the 1990s to describe how organisations can realise the business value of ICT investments and provide normative guidance in the form of frameworks and methods (Lin, Pervan and McDermid, 2007). Of the various streams of BR research, the Benefits Management Model (BMM) and research related to this, is widely considered the most influential (Waring, Casey and Robson, 2018). We therefor focus our study on this stream of research.

Elements from the BMM literature have been embraced by practice communities and selected by public entities to assist public digitalisation efforts in countries such as the UK, Australia, New Zealand and Norway (e.g., Hellang, Flak and Päivärinta 2013; Burton-Jones et al., Forthcoming). However, the different frameworks and methods do not offer guidance on how to facilitate inter-organisational digitalisation efforts that aim to realise benefits beyond single organisations or at the societal level (Flak, Solli-Saether and Straub, 2015; Lönn, Juell-Skielse and Päivärinta, 2016). Ward and Daniel (2012) state the realisation of benefits when multiple entities are involved is highly challenging, because they often represent strategically distinct starting points. 
Furthermore, if the benefits of ICT investments are dependent on changes perceived as unachievable or highly problematic, the BMM advises against pursuing the related benefits (Ward and Daniel, 2012). In short, the BMM approach has been developed to support single organisations but provides no support for current organisational practices in the public sector concerning belonging to a network aiming to realise societal benefits through digitalisation efforts.

There is clearly a gap between currently available BMM frameworks recommended for and used in practice and the actual digitalisation contexts facing the practice community. Consequently, more research is needed, specifically to understand the impact of the BMM practices (Doherty, 2014) and to increase knowledge regarding the challenges of managing BR in complex, inter-organisational digitalisation efforts (Flak, SolliSaether and Straub, 2015; Lönn, Juell-Skielse and Päivärinta, 2016).

Motivated by this gap our study explores the following research question: What are the challenges of using BMM frameworks in inter-organisational digitalisation projects?

We study the problem by investigating BR in an inter-organisational project among both public and private organisations in Norway. In the Telemedicine Innovation Project (TIP), several actors, including municipalities and a hospital, sought to develop and implement novel, integrated healthcare services for chronically ill patients via ICT. While the overall goals were shared among the participants, there were tensions and challenges in the process of realising them, which makes the case useful for answering the research question.

We analyse the case using key concepts from the BMM literature (Ward and Daniel, 2012) to understand it and uncover the shortcomings of existing frameworks.

\section{Related research}

\subsection{Benefits realisation in information systems research}

When reviewing the history of the Information systems (IS) discipline, Hirschheim and Klein (2012) position benefits realisation as an extension of the IT evaluation literature. As pointed out by Frisk, Bannister and Lindgren (2015), the available literature of IT evaluation is extensive and thus too diverse to use as a basis for our research. Rather, we are focusing on one of the specific research streams related to IT evaluation, namely what is commonly referred to as benefits management (BM) or benefits realisation (BR). The BR literature is largely a response to recurring challenges related to implementation of ICT and the realisation of benefits from such efforts (Doherty, Ashurst and Peppard, 2012; Marnewick, 2017; Ghildyal, Chang and Joiner, 2018).

Recently, Waring, Casey and Robson (2018) provide an excellent overview of BR frameworks or classification schemes within the IS discipline, twelve in total. Five of the frameworks, as among them Active Benefits Realisation (Remenyi and Sherwood-Smith, 1998), Great IT Benefit Hunt (Farbey, Targett and Land, 1994) and Benefits Management (Ward, Taylor and Bond, 1996) are presented as independent and original contributions. Six of the remaining frameworks, for instance Benefits Dependency Network (Ward and Daniel, 2006) and the Benefits Realization Capability Model (Ashurst, Doherty and Peppard, 2008) build on the benefits management approach by Ward, Taylor and Bond (1996).

Although there has been a substantial amount of research on BR, there is disagreement as to whether BR practices improve our ability to realise benefits from IT investments (Peppard, Ward and Daniel, 2007) or not (Badewi, 2016). Despite this, BR approaches have been adopted in practice, where the Benefits management model (BMM) has been the most influential (Mohan, Ahlemann and Braun, 2016; Waring, Casey and Robson, 2018). However, few empirical studies on how the BM process occur in practice can be found (Doherty, 2014; Frisk, Bannister and Lindgren, 2015), especially from public sector (Juell-Skielse, Lönn and Päivärinta, 2017) and inter-organisational collaborations (Lönn, Juell-Skielse and Päivärinta, 2016).

Inter-organisational collaboration is increasing but the BMM literature offers little or no support for complex settings (Flak, Solli-Saether and Straub, 2015). The phenomenon of complexity is either only briefly described (Seemann, Dinesen and Gustafsson, 2013) or just mentioned as a consequence of inter-organisational collaboration (Flak, Solli-Saether and Straub, 2015). In a notable exception, Askedal (2019) explored complexity in an inter-organisational digitalisation effort and identified challenges such as tensions between participating organisations and external conditions (e.g. regulatory, financial and political structures). Although Askedal 
(2019) contributes to a better understanding of the challenges involved, this research does not provide normative directions for how to address this pressing issue.

Thus, there is clearly a gap between existing BMM frameworks and the challenges facing practitioners. To address this gap, more knowledge is needed to understand the challenges of BM in inter-organisational digitalisation efforts (Lönn, Juell-Skielse and Päivärinta, 2016). Consequently, BMM literature (Ward and Daniel, 2006) is used as the theoretical foundation for this paper and key concepts from BMM are used as a basis for analysing the usefulness of BM in inter-organisational settings. The next section provides details about the key concepts in the BMM.

\subsection{The benefits management model}

The BMM literature has developed practical approaches to identify, define, plan, track and realise the benefits of IT investments. Benefits management is defined by Ward and Daniel $(2012$, p. 8) as 'the process of organizing and managing such that the potential benefits arising from the use of IS/IT are actually realized'.

Table 1 presents brief definitions of key concepts based on Ward and Daniel (2012). These key concepts are central for understanding the essence of the BMM literature and will later be used as an analytic lens for answering the research question.

Table 1: Key concepts from the BMM literature (Ward and Daniel, 2012, p. 70-73, 98, 107)

\begin{tabular}{|l|l|}
\hline $\begin{array}{l}\text { BMM literature } \\
\text { key concepts }\end{array}$ & Definition \\
\hline Business drivers & $\begin{array}{l}\text { Issues which executive and senior managers agree mean the organisation needs to make changes- } \\
\text { and the time scales for those changes. Drivers can be both external and internal but are specific to the } \\
\text { context in which the organisation operates. }\end{array}$ \\
\hline $\begin{array}{l}\text { Investment } \\
\text { objectives }\end{array}$ & $\begin{array}{l}\text { A set of statements that describe what the organisation is seeking to achieve from the investment. } \\
\text { They should include a description of the situation upon the successful completion of the investment. }\end{array}$ \\
\hline Business benefit & $\begin{array}{l}\text { An advantage on behalf of a stakeholder or group of stakeholders. This implies that the benefits are } \\
\text { owned by the individuals or groups who want to obtain value from the investment. }\end{array}$ \\
\hline Benefit owner & $\begin{array}{l}\text { An individual who will take responsibility for ensuring that a particular benefit is achieved. This usually } \\
\text { involves ensuring that the relevant business and enabling changes progress according to plan and are } \\
\text { achieved. Due to the need to ensure task completion, the benefit owner is usually a senior manager. }\end{array}$ \\
\hline $\begin{array}{l}\text { Business } \\
\text { changes }\end{array}$ & $\begin{array}{l}\text { New ways of working required to ensure that the desired benefits are realised. These will be the new, } \\
\text { ongoing ways of working in the organisation - at least until the next change initiative. }\end{array}$ \\
\hline Enabling changes & $\begin{array}{l}\text { Changes that are prerequisites for achieving the business's changes or that are essential to bring the } \\
\text { system into effective operation within the organisation. Enabling changes are usually 'one-off' } \\
\text { activities rather than ongoing ways of working. }\end{array}$ \\
\hline Enabling IS/IT & $\begin{array}{l}\text { The information systems and technology required to support the realisation of identified benefits and } \\
\text { to enable the necessary changes to be undertaken. }\end{array}$ \\
\hline Change owner & $\begin{array}{l}\text { An individual or group who will ensure that an identified business or enabling change is achieved } \\
\text { successfully. }\end{array}$ \\
\hline
\end{tabular}

A recent paper indicates that the challenges for realising inter-organisational benefits are already visible in the early phases of a project when benefits are identified and structured and when benefits' realisation is planned (Askedal, 2019). During these steps, The BMM model suggest that three questions are asked: 1) Why is the investment being made? 2) What types of benefits are the organisation expecting to achieve? 3) How can a combination of business changes and IT deliver those benefits? (Ward and Daniel, 2012, p. 85).

The first question (Why is the investment being made?) addresses business drivers. These are strategic and often externally oriented, although they can also be internal. A driver analysis is suggested to identify and understand the reasons for change. When the business drivers are identified, the BM literature suggests that key stakeholders agree on investment objectives, which must address the business drivers and be expressed so that stakeholders will commit to them. When both business drivers and investment objectives are identified and agreed upon, the objectives should be linked to the drivers. If an objective does not link to a driver, it should be removed due to the challenges of developing a valid business case ( Ward and Daniel, 2012). To help answer the second question (What types of benefits are the organisation expecting to achieve?), Ward and Daniel (2012) propose identifying the business benefits specific to individuals or groups by examining the investment objectives and identifying the type of improvements that will be gained if the objectives are achieved. Finally, the third question (How can a combination of business changes and IT deliver those benefits?) can be answered by developing a visual outcome map which builds a shared perception of the relationship between changes and benefits (e.g. a benefits dependency network - BDN). A BDN is a visual tool 
to relate business drivers, investment objectives and business benefits to the required changes (both business changes and enabling changes) and have been used in recent studies (Coombs, 2015; Villumsen, Nøhr and Faxvaag, 2018). Based on the identified changes, the enabling IS/IT can be considered. This illustrates a key tenet in the BMM approach, namely, allowing organisational strategy rather than technology to be the driver of organisational change. The mapping process provides an increased understanding of dependencies between changes and benefits and serves as a reminder that the benefits will only be realised if the required changes are successfully implemented.

However, if necessary changes (business changes or enabling changes) are problematic or impossible to achieve, it is suggested that the dependent benefits are removed from the project, as they are seen as an investment risk (Ward and Daniel, 2012). Another recommendation is that a benefit owner should be assigned to each of the benefits, and change owners also should be assigned. The model recommends that both change owners and benefit owners be individuals. However, the roles should be owned by the organisation, because members of a project seldom can perform actions that enable the required changes or realise the benefits.

The project owner has the overall responsibility for getting a project to achieve its' goals, but may choose to delegate responsibility for benefits to a distinct person - the benefits owner. Ward and Daniel (2012) state the importance of understanding the relationship and balance between the benefit owners and change owners. If change owners gain no or few benefits, they may not be prepared to put in the effort to make the changes required for realising the associated benefits. If this is identified at an early stage, such issues can be addressed by considering re-scoping or restructuring the project (Ward and Daniel, 2012).

\section{Method}

A qualitative research design was applied to explore our research question. Based on its nature, a single case study research design with an interpretive approach was deemed appropriate to explore BM in interorganisational digitalisation efforts. Case analysis is frequently used in IS research (Orlikowski and Baroudi, 1991; Chen and Hirschheim, 2004) and allows technology to be studied in a natural setting. This enables an increased understanding of emerging phenomena and can facilitate theory building through observations of practice (Mueller and Urbach, 2017). More precisely, applying a case study design in this study allows us to gain an in-depth understanding of the emerging phenomenon of BM in inter-organisational settings and further, provide novel contributions to theory by suggesting propositions to extend the BMM literature to cater for inter-organisational digitalisation efforts. A single case study does not allow us to generalize the findings to other inter-organisational digitalization projects. We rather seek to utilize the case study's potential for analytic generalizability (Walsham, 1995; Flyvbjerg, 2006) as we develop a contribution to the BMM literature.

We selected an ongoing, inter-organisational project from the public health sector in Norway as our case. Overall, the Norwegian health sector is divided into specialist and primary healthcare. Regional boards govern the hospitals, which are financed by a combination of block grants and activity-based financing. Municipalities are responsible for providing primary health and care services to their inhabitants, financed by block grants and taxes. General practitioners (GPs) constitute the first line of health care. The majority of GPs are selfemployed but have contractual relationships with municipalities and function as gatekeepers to specialist services (Ringard et al., 2013).

The project (TIP) involved three municipalities, a hospital, a university, a technology vendor and a consulting company. The project aimed to establish telemedicine services for chronic care patients in a region consisting of 30 municipalities. We used semi-structured interviews, participant observation and document analysis. Fifty semi-structured interviews with stakeholders were conducted by one of the authors between September 2017 and February 2018 (see table 2). The selection of informants was based on the stakeholder typology of Mitchell, Agle and Wood (1997) to determine key stakeholders. When the interviews were conducted, only two of the municipalities were actively participating in the project. Thus, our respondents only represent two of the three municipalities initially involved in the project.

An interview guide was developed based on the BMM literature (Ward and Daniel, 2012) to cover relevant themes such as current and future healthcare services (including practice, technology and telemedicine) in 
addition to core aspects of the case (e.g. drivers, potential benefits, enabler, inhibitors, experiences and organisational changes). The interviews were recorded, transcribed and coded in NVivo by one of the authors.

Besides the interviews, field notes from participant observation were used, because two of the authors were directly engaged with the project and participated in regular project activities such as meetings, workshops and seminars. Finally, project documentation (e.g. a project charter, project directive) was analysed by one of the authors.

The evaluation of the empirical material was first used to create a coherent story line and overview of key events in the project. Next, we zoomed in on challenges related to BMM within and between the participating organisations. The analysis was discussed and refined through several discussions between all the authors. For this step of the analysis, a specific focus was given to the different versions of the project charter document and to 12 key interviews with representatives from participating organisations.

Table 2: Overview of interviews

\begin{tabular}{|c|c|c|c|}
\hline $\begin{array}{l}\text { Organisation/societal } \\
\text { stakeholders }\end{array}$ & Sector & Role (N) & $\begin{array}{l}\text { Number of } \\
\text { interviews }\end{array}$ \\
\hline Municipality 1 & Public & $\begin{array}{ll}\text { - } & \text { Top/service/department manager (8) } \\
\text { - } & \text { Project manager/work package leader (2) } \\
\text { - } & \text { Advisor (5) } \\
\text { - } & \text { Public health officer/GP (3) } \\
\text { - } \quad & \text { Nurse/other healthcare professional (2) } \\
\text { - } & \text { Senical citizen council (1) }\end{array}$ & 23 \\
\hline Municipality 2 & Public & $\begin{array}{ll} & \text { Top/service/department manager (3) } \\
\text { - } & \text { Project manager/work package leader (1) } \\
\text { - } & \text { Advisor (1) } \\
\text { - } \quad \text { Nurse/other healthcare professional (2) } & \text { Technical personnel/ICT (1) } \\
\end{array}$ & 8 \\
\hline Hospital & Public & $\begin{array}{ll}\text { - } & \text { Top/service/department manager (3) } \\
\text { - } & \text { Advisor (2) } \\
\text { - } & \text { Doctor (3) } \\
\text { - } & \text { Nurse/other healthcare professional (2) } \\
\text { - } & \text { Technical personnel/ICT (1) } \\
\end{array}$ & 12 \\
\hline University & Public & $\begin{array}{ll}\text { - } & \text { Top/service/department manager (1) } \\
\text { - } & \text { Project manager/work package leader (1) } \\
\text { - } & \text { Professor/researcher (1) }\end{array}$ & 3 \\
\hline Technology vendor & Private & - $\quad$ Top/service/department manager (2) & 2 \\
\hline Consulting company & Private & - $\quad$ Project manager/work package leader (1) & 1 \\
\hline Other & & - User representative (1) & 1 \\
\hline Total & & & 50 \\
\hline
\end{tabular}

\section{Results}

This section outlines the results from our analyses. First, we describe the case. Second, we identify practical challenges for managing benefits in inter-organisational settings using the key concepts from the BMM literature.

\subsection{The Telemedicine Innovation Project - TIP}

The Telemedicine Innovation Project (TIP) started in 2016 as a partnership between public and private organisations in an effort to develop new and innovative solutions addressing the expected challenges of future healthcare service provision. According to the project charter, the overall goal was: "To test and evaluate a joint telemedicine solution for remote monitoring and treatment of patients with chronic diseases or comorbidity among 30 municipalities, providing good healthcare services with less use of healthcare resources". Monitoring and treating patients via telemedicine represented a substantial change from the existing practice of face-to-face care and, thus, required service innovation. In addition, the TIP represented organisational innovation in that the distribution of service responsibility could be altered among the actors. For instance, a central aim was to prevent the exacerbation of chronic diseases and reduce hospitalisation, which might shift the care load away from hospitals and to municipal services.

The participants included three municipalities (responsible for offering telemedical services to patients with chronic diseases), one hospital (responsible for developing the triage and treatment protocols), one university 
(responsible for research), one technology vendor (providing the telemedical solution) and one consulting company (responsible for project management in collaboration with one of the municipalities that is the project owner).

The participants developed standards for a telemedical patient pathway (i.e. enrolment, service initiation, follow-up and ending) and treatment triage for patients with chronic diseases (i.e. targeting patients with either chronic-obstructive pulmonary disease (COPD), heart failure, type 2 diabetes, mental health issues or a combination of diseases).

They also implemented and further developed the technology and infrastructure for telemedical services. This included a patient kit consisting of devices such as a blood pressure meter, glucose meter, pulse and oxygen saturation meter, scale and other technology (the device kit was tailored for different diagnoses) as well as a dedicated tablet which collected and forwarded patient measures to the telemedicine system. The tablet was also the interface for the patients' communication with health personnel (e.g. questionnaire, video chat).

A telemedical centre was established in each of the three municipalities to receive and display information from the remotely monitored patients. The centres were staffed by health personnel interacting with the patient both in planned, follow-up calls and ad hoc situations, for example in response to alarms triggered by deviating values from the devices or by questionnaire responses. Much of the two first years was spent on preparatory and developmental activities. The project was delayed by organisational challenges which will be described in the next section.

\subsubsection{Case development and tensions}

As the above description suggests, the TIP made substantial progress but also encountered several challenges. Initially, the hospital was the project owner. However, the municipalities considered this arrangement awkward, considering that previous experience suggested that telemedicine treatment would increase municipal costs and responsibilities and not lead to short-term efficiency gains for them. In addition, the enrolment of patients into the TIP triggered substantial tensions among the partners. The project's service design report stated that:

Citizens suffering from one of the defined chronical diseases can apply for telemedical services through the TIP. ... The municipalities assess the application and by defined criteria set by the TIP, decide to include the patient into the TIP. Based on the patient conditions, the service is given as a preventive service or as a replacement for other municipal healthcare services.

Discussions arose on the inclusion criteria for the patients and on who should define these. While the hospital was assigned the task of developing treatment protocols, their diagnosis-centred mode of working clashed with the municipalities' needs-based processes of assigning health services. This can be related to differences in the allocation of national funding for municipalities and hospitals. Moreover, the ambition to prevent the development of disease meant that health services might be offered to 'too healthy' patients, that is persons with no formal right to municipal care services. Discussions arose, for example regarding whether the hospital was entitled to make decisions on service allocation, which would impact other actors (the municipal partners), since these decisions would increase the municipalities' service load, possibly beyond the boundaries of the project. After serious discussions during the first half of 2016, project ownership and management were transferred from the hospital to one of the participating municipalities. An external consultancy company was engaged to handle project management with the municipality.

We have actually lost one year...because the first year was spent on discussions that didn't produce any results. ...At the same time, the trouble taught us a lot of things. It's not completely useless, but we didn't get progress in the work packages and in developing a telemedical patient pathway, defining inclusion criteria and enrolling patients that we should have had. ...It is an exceptionally challenging project (manager, municipality 1).

The shift in ownership and project management caused substantial delays in the project. The complex nature of the project caused several further challenges for the consortium related to the different perceptions of objectives and priorities. The analysis in the next section relates these challenges to core of BMM literature. 


\subsection{Analysis}

We employ the key concepts from the BMM literature as introduced in Section 2.2, Table 1 to illustrate where challenges in the project emerged. The results of the analysis are summarised in Table 3 . In one column, we present the official and formal handling of the various BMM aspects, and in the other, we account for how the various participants perceived and related to these. The analysis of the experiences led to the identification of five challenges.

The analysis revealed that the business drivers were mostly aligned among the TIP partners, even though some were more concerned about their own organisation (internal drivers) than societal (external) drivers. However, no practical challenges have been identified in relation to this concept.

The overall goal of the TIP, identified as investment objectives, has been unchanged throughout the project. However, the analysis revealed that the meaning of 'a joint telemedical solution' differed among the partners. Some interpreted it to be a joint way of providing healthcare services, and some interpreted it to be a joint technological solution (which was the originally intended meaning). In addition, there were varying thoughts about the priority of the objectives (good healthcare services, less use of healthcare resources) among the TIP partners. During the project, the investment objective of 'a joint telemedical solution' were difficult to fully achieve because it depended on factors outside the TIP's control, such as technical infrastructure across Norwegian healthcare provider.

There has been a strong focus and desire to realise benefits in the TIP, but practical work with benefits management has been lacking. A list of expected benefits was formulated in the beginning of the project and was revised in late 2018. Some of the expected benefits were formulated and related to a group of stakeholders at a societal or inter-organisational level, such as 'Cost-effective use of healthcare services' (hospitals, GPs, municipalities)'. Other expected benefits did not address any particular stakeholder group, such as the 'cost-effective management of ICT'. Defining business benefits at a societal and interorganisational level has challenged the benefit ownership in the TIP. Furthermore, it has proven challenging to measure the 'cost-effective use of healthcare services across hospitals, GPs and municipalities' with the use of a socioeconomic analysis. The partners have a range of ways of reporting their services which require enormous effort in collecting and mapping the necessary information to cover the societal perspective of the expected benefit. In addition, the partners have divergent thoughts about when they expect the benefits to be realised - some within the TIP timeframe and others in a longer perspective, which have caused discussions.

Regarding benefits, it is important to not only focus on the benefits right here and now. We, both hospital and municipalities, must also think of the benefits which apply in the future. ...If it's 'right here and now' that matters, I think the overall benefits won't be good enough (clinical staff, hospital)

The head of the TIP steering committee was formally responsible for realising the TIP's investment objectives, but no one is formally appointed to own each of the expected benefits. In practice, there is a lack of benefit ownership. The expectation apparently was that, when benefits were formulated at an 'abstract' level, everybody should feel ownership. However, when everybody is responsible, no one takes action. Only one informant viewed his organisation to be responsible for coordinating operational healthcare services and facilitating discussions among the healthcare providers necessary for understanding the patient pathway.

We must do this anyway - somebody must do the job. Somebody must coordinate the operation. ... The discussions we have across and between municipalities and between municipalities and the hospital are really important for understanding the patient pathway (manager, municipality 1).

It also proved impossible for the head of the steering committee to be responsible for ensuring the realisation of all expected benefits without identifying and empowering benefit owners in the participating organisations and at a societal level. 
Table 3: BMM key concept analysis

\begin{tabular}{|c|c|c|}
\hline $\begin{array}{l}\text { BMM } \\
\text { literature key } \\
\text { concepts }\end{array}$ & $\begin{array}{l}\text { Evolution of concept in TIP project charter } \\
\text { versions }\end{array}$ & $\begin{array}{l}\text { Perception among participants, as reflected in } \\
\text { interviews }\end{array}$ \\
\hline $\begin{array}{l}\text { Business } \\
\text { drivers }\end{array}$ & $\begin{array}{l}\text { The overall drivers relate to the expected } \\
\text { challenges of future healthcare service provision } \\
\text { (imbalance of number of patients who need help } \\
\text { and healthcare professionals available). } \\
\text { Changes during the project: None }\end{array}$ & $\begin{array}{l}\text { Most participants pointed to future challenges of } \\
\text { service provision and think technology can assist } \\
\text { with the provision of qualitative and effective } \\
\text { healthcare services from a societal perspective. } \\
\text { However, some of the informants focused on their } \\
\text { own organisation. }\end{array}$ \\
\hline $\begin{array}{l}\text { Investment } \\
\text { objectives }\end{array}$ & $\begin{array}{l}\text { The overall goal was to establish a joint } \\
\text { telemedical solution for patients with chronic } \\
\text { diseases/comorbidity, providing good healthcare } \\
\text { services with less use of healthcare resources. } \\
\text { Changes during the project: None }\end{array}$ & $\begin{array}{l}\text { The participants varied in their prioritisation, e.g. } \\
\text { targeting chronic patients rather than high-demand } \\
\text { patients, the weighting of service quality versus } \\
\text { costs etc. The understanding of what a joint } \\
\text { telemedical solution meant (technology solution or } \\
\text { service collaboration) differed among the } \\
\text { participants. }\end{array}$ \\
\hline $\begin{array}{l}\text { Business } \\
\text { benefit }\end{array}$ & $\begin{array}{l}\text { Expected benefits pr. 2018: 1) Cost-effective } \\
\text { management of ICT, } \\
\text { 2) Increased collaboration among healthcare } \\
\text { providers of telemedical services, } \\
\text { 3) Cost-effective use of healthcare services } \\
\text { (hospitals, GPs, municipalities), 4) Patient } \\
\text { empowerment and increased quality of life, } \\
\text { 5) Increased competence of telemedical pathways } \\
\text { in the region and 6) Experiences and models of } \\
\text { best telemedical practice. } \\
\text { Changes during the project: Reformulation of } \\
\text { expected benefits in late 2018: e.g. from 'uniform } \\
\text { ICT interaction...' to 'increased collaboration...' }\end{array}$ & $\begin{array}{l}\text { The participants' focus was mostly on cost- } \\
\text { effective services and, to some extent, increased } \\
\text { quality of life for patients and building knowledge of } \\
\text { and experiences with telemedical practice. The } \\
\text { participants discussed benefits generally and were } \\
\text { mainly concerned about the time perspective for } \\
\text { realising expected benefits. Additionally, } \\
\text { informants representing municipalities point out } \\
\text { that the TIP must realise some benefits in its own } \\
\text { organisation. }\end{array}$ \\
\hline Benefit owner & $\begin{array}{l}\text { The head of the TIP Steering Committee was } \\
\text { formally responsible for realising the TIP's } \\
\text { investment objectives. No one was appointed to } \\
\text { be formally responsible for the benefits. } \\
\text { Changes during the project: None }\end{array}$ & $\begin{array}{l}\text { One informant saw their own organisation as } \\
\text { responsible for coordinating operational healthcare } \\
\text { services and facilitating discussions among the } \\
\text { healthcare providers necessary for understanding } \\
\text { the patient pathway. The others did not discuss } \\
\text { ownership of the expected benefits but discussed } \\
\text { them generically. }\end{array}$ \\
\hline $\begin{array}{l}\text { Business } \\
\text { changes }\end{array}$ & $\begin{array}{l}\text { The overall telemedical concept remained, but its } \\
\text { concretisation in the telemedical patient pathway } \\
\text { (enrolment, service initiation, follow-up, ending) } \\
\text { necessitated changes in patient recruitment } \\
\text { (criteria and processes), as well as in the service } \\
\text { provision model (remote care). } \\
\text { Changes during the project: None }\end{array}$ & $\begin{array}{l}\text { The more concrete pathway description triggered } \\
\text { tensions among partners, as there were divergent } \\
\text { perceptions of how to select patients (disease vs. } \\
\text { need), the allocation of gatekeeper/decision } \\
\text { authorities (by project or municipalities?) and type } \\
\text { of service (preventive service vs. replacement for } \\
\text { other services). }\end{array}$ \\
\hline $\begin{array}{l}\text { Enabling } \\
\text { changes }\end{array}$ & $\begin{array}{l}\text { Six enabling changes within the TIP time frame } \\
\text { are defined (e.g. develop service design and } \\
\text { patient pathways, including procedures for } \\
\text { recruiting patients from municipalities and } \\
\text { hospitals, establish knowledge about the potential } \\
\text { and prerequisites for the benefits realisation of } \\
\text { telemedical services in operation). } \\
\text { Changes during the project: Two new } \\
\text { (cooperation agreement, enrolment of patients), } \\
\text { one removed (test/evaluate technology and } \\
\text { infrastructure across healthcare providers) }\end{array}$ & $\begin{array}{l}\text { Informants were concerned about assorted } \\
\text { elements of the prerequisites (enabling changes) } \\
\text { within the TIP timeframe, such as how to enrol } \\
\text { enough patients into the TIP. Additionally, some } \\
\text { are pointing to one enabling change outside the } \\
\text { TIP's control which is crucial for a sustainable } \\
\text { business change across the TIP partners: the } \\
\text { difference in the allocation of national funding for } \\
\text { healthcare services to municipalities, hospitals and } \\
\text { GPS. }\end{array}$ \\
\hline Enabling IS/IT & $\begin{array}{l}\text { Several IS/ITs are listed: telemedical solution } \\
\text { including treatment triage, patient kit including } \\
\text { tablet and devices for measurement, municipal } \\
\text { health record, web portal for logistic management, } \\
\text { machine learning and a self-help programme for } \\
\text { mental health. } \\
\text { Changes during the project: Some new (e.g. } \\
\text { logistic management, machine learning). }\end{array}$ & $\begin{array}{l}\text { The partners reflected on the TIP technology, } \\
\text { especially related to machine learning (e.g. distrust } \\
\text { among TIP partners about the motive for } \\
\text { implementation) and the selection of the } \\
\text { telemedical solution (e.g. tensions among TIP } \\
\text { partners). Because the chosen telemedical solution } \\
\text { was selected at an early stage of the TIP, it was a } \\
\text { commercial, off-the-shelf answer without an } \\
\text { innovation. Nevertheless, it still needed TIP } \\
\text { customisation, which was time- consuming. } \\
\text { However, the informants were more concerned } \\
\text { about organisational issues than the technology. }\end{array}$ \\
\hline Change owner & $\begin{array}{l}\text { The operating service division in municipality } 1 \\
\text { (project owner) is formally responsible for } \\
\text { delivering the enabling changes within the TIP } \\
\text { timeframe to the head of the TIP steering } \\
\text { committee. } \\
\text { Changes during the project: None }\end{array}$ & $\begin{array}{l}\text { Some of the informants pointed to the disparate } \\
\text { work packages in the TIP when addressing the } \\
\text { responsibility for successfully achieving the } \\
\text { enabling changes within the TIP timeframe. Most } \\
\text { informants pointed to external stakeholders } \\
\text { (outside the TIP's control) for the successful } \\
\text { achievement of enabling changes. }\end{array}$ \\
\hline
\end{tabular}


The business change, identified as the overall telemedical concept (descriptions of how to enrol patients, which patients to include, healthcare provision through municipal telemedical centres), was defined as a municipal service and did not involve the hospital, except for enrolling 'their' patients (chronic diseases). The overall telemedical concept did not change during this project but caused the most challenges and triggered several tensions among the TIP partners.

This is a municipal service. Usually, municipalities cannot get involved in hospital services, and vice versa. ... We don't talk about diseases in the municipality - they do it in hospital (manger, municipality 2).

There is a missing link between the business change (which happens in municipal service provision) and the expected benefits at an inter-organisational level.

Enabling changes were identified in the project's documents to be six enabling changes within the TIP timeframe, both inter-organisational and organisational. The partners mostly focused on how to deal with issues such as enrolling enough patients into the project and including other municipalities in the region into the TIP. In addition, conditions outside the TIP partners' control were identified in the project's documents. For instance, the integration between the telemedical solution and the electronic health record was not pursued because there were ongoing national initiatives to resolve this. Several discussions among the participants highlighted the challenges that resulted from the financing system being separately handled for municipalities, hospitals and GPs.

What I think is the biggest threat for a continuation of the TIP is the financing system. ... It is a lot of goodwill in municipalities, but you cannot just live on goodwill. You need appropriate incentives for it to work (manager, technology vendor).

When the municipality started to offer additional services, it was not followed by additional funds from the project or government. While the participants knew that financing would become an issue after the project period, they also considered any action to change the current funding system to be beyond their control. However, the analyses suggest that enabling changes outside the TIP's control are likely to hinder sustainable business changes by negatively affecting the realisation of business benefits and, thus, indirectly hindering the successful achievement of investment objectives.

Several technologies were needed for the provision of telemedical services in the TIP. These have been identified as enabling IS/IT and can be found at two levels (similar to the enabling changes): within the TIP'S control (organisational or inter-organisational), such as municipal health records and telemedical solution, and out of the TIP's control, such as technology infrastructure across levels of healthcare providers. The main technologies have remained the same from the beginning of the project. While technology played a significant role in the TIP and there were some challenges, these obtained far less attention than the organisational issues among the partners.

TIP is not a technology project. It is an organisational project. ... The challenge is not the technologythat is pretty straightforward (manager, consultant company).

Still, our analysis points to the perception of enabling IS/IT as being out of the TIP's control, which led to the re-scoping of the project charter's formulation of benefits (from 'uniform ICT interaction...' to 'increased collaboration') and the understanding of the investment objectives. (The meaning behind a 'joint telemedical solution' changed from a joint technology solution to service collaboration).

The analysis has identified enabling changes and enabling IS/IT at multiple levels for sustainable services in a TIP. These two concepts provide the basis for change owners in the BMM literature, which addresses the need for identifying change owners in the TIP at the same levels. Our analysis confirmed this, as change owners have been identified both within and outside a TIP's control. Moreover, the analysis identified uncertainty regarding change owners for enablers within the TIP.

There are so many involved, so who is responsible for what? (manager, municipality 2). 
According to the project documents, the service providing unit in municipality 1 (project owner) was responsible for achieving the project's enabling changes. However, the service providing unit did not have the ability to ensure that the identified business or enabling changes beyond their own organisation were successfully achieved. Some of the TIP partners mentioned the different TIP sub-projects as responsible for achieving enabling changes within TIP, rather than the formally responsible operative healthcare service provider. Besides change owners within the TIP, most partners pointed out the importance of external change owners for the successful achievement of enabling changes.

I think this project really highlights how it had been advantageous to be one healthcare service and not two. And that is a considerably different and greater discussion (manager, municipality 1).

Well, it's not all you [TIP] can decide. You cannot decide that 30 municipalities should give preventive services. Sorry, that's not the world! ... Think about democracy. We choose politicians. In the 30 municipalities, the citizens have chosen their politicians. Who decides? Yes, it's the politicians. ... We have the same legislations, but there are interpretation possibilities (manager, municipality 2).

The Norwegian statutory financing system is highlighted as a crucial enabler for sustainable telemedical services across healthcare providers (see enabling changes and business change). Concerning this, TIP partners indicated government or politicians, for example as appropriate groups of change owners with the power to address enablers that were out of the TIP's control.

\section{Discussion}

Our analysis revealed several practical challenges to the inter-organisational TIP project. These seem related to two of the three questions Ward and Daniel (2012) suggest are important for establishing a solid foundation for enabling the realisation of benefits:

Q2) What types of benefits are the organisation expecting to achieve?

Q3) How can a combination of business changes and IT deliver those benefits?

Challenges related to these two questions are indirectly affecting question Q1) why is the investment being made? This is because the scope of expected benefits (Q2) in addition to the premises for achievable changes, including prerequisites (Q3), set the conditions for the realistic achievement of the investment (Q1). When the intended investments involve more than one actor, the distribution of benefits and changes among actors need to be addressed.

In the following section, we discuss five challenges to the BMM literature and suggest propositions for each of the challenges. Finally, a summary of our contributions is provided in Table 4.

\subsection{Challenge 1: Formulating the expected benefits}

The BMM literature outlines the identification of expected benefits as an essential task initially in a project. This task should be linked to the investment objectives - all in the perspective of a single organisation as advantages specific to individuals or groups and formulated in a measurable way (Ward and Daniel, 2012). Our TIP analysis revealed a situation very different from the assumption in BMM literature. In TIP, most of the expected benefits were formulated either at a societal or inter-organisational level (e.g. the cost-effective use of healthcare services like (hospitals, GPs, municipalities) or without targeting any specific stakeholder group (e.g. the cost-effective management of ICT). In public inter-organisational digitalisation efforts, the production of societal purposes is often the shared, overall goal (Gil-Garcia, 2012; Lönn, Juell-Skielse and Päivärinta, 2016).

The formulation of expected benefits at the societal and/or inter-organisational level caused other challenging issues in TIP. The measurement of expected benefits at societal or inter-organisational levels was challenging due to variations in documentation practices among the TIP partners (e.g. diseases in hospitals vs. needs in municipalities). We also observed a lack of benefit ownership, possibly due to the nature of the benefits. As few benefits were directly linked to each of the participating organisations, the motivation to function as a benefit owner was limited. While the TIP partners acknowledged the importance of what they could achieve together, they struggled to see immediate benefits for their individual organisations. This situation hindered the progress of TIP. Consequently, we argue that it is critical to formulate expected benefits at the organisational level, in addition to societal and inter-organisational levels. 
Proposition for overcoming Challenge 1:

1. The identification of benefits at the societal, inter-organisational and organisational levels is required to realise benefits at the societal, inter-organisational and organisational levels.

\subsection{Challenge 2: Establishing ownership for expected benefits}

The analysis of TIP data revealed limited ownership among the TIP partners concerning the expected benefits. The formal benefit owner of TIP was the head of the TIP steering committee. This is, to some extent, along the lines of existing BMM literature, suggesting that an individual person holding a high position (in the TIP and in his or her own organisation) should have this role. However, our findings suggest that this may not be sufficient in an inter-organisational project like the TIP. Despite a common agreement and motivation to contribute to the production of societal purposes, the TIP's partners are autonomous. The head of the TIP steering committee has limited influence over other TIP partners, as each is bound by his or her own organisational priorities and structures. TIP benefits, at least the economic ones, were largely expected to materialise on the societal level and certainly not within municipalities. This understanding resulted in low degrees of benefit ownership at the levels at which benefits were expected to be realised.

Proposition for overcoming Challenge 2:

2. Benefit owners at the societal, inter-organisational and organisational levels are necessary to realise benefits at societal, inter-organisational and organisational levels.

\subsection{Challenge 3: Understanding necessary business changes}

During the first two years of the TIP project, major challenges and tensions occurred that could have led to the termination of the TIP. Several tensions were triggered by the business changes and the telemedical concept, especially the part concerning the enrolment of TIP patients. These challenges were not discussed in the project development phase and were first acknowledged when the project neared the launching of the actual service. The TIP telemedical patient pathway was arguably a service innovation, as it intervened and changed healthcare organisations, structures, healthcare professionals and patient roles. Existing BMM literature does not examine business changes intervening in the multiple organisations required for ensuring the realisation of societal and inter-organisational benefits. Instead, the literature suggests removing benefits if changes are problematic to achieve, as problematic changes are seen as investment risks. Our case indicates that existing BMM advice is insufficient, as it will limit societal innovation initiatives, including the realisation of potential societal benefits.

Based on results from the TIP case, identifying and understanding the magnitude of necessary business changes is essential to inter-organisational digitalisation efforts aiming for the production of societal purposes.

Proposition for overcoming Challenge 3:

3. Identifying necessary business changes at the societal, inter-organisational and organisational is required.

\subsection{Challenge 4: Understanding enabling changes}

The BMM literature defines enablers either as prerequisites for sustainable service (called enabling changes) or the technology required for benefits realisation (called enabling IS/IT) in the perspective of single organisations (Ward and Daniel, 2012). The analysis of the TIP data revealed enablers at two levels: 1) within the TIP, either as inter-organisational or organisational enablers and 2) outside the TIP's control (e.g. the Norwegian statutory financing system or digital infrastructure).

TIP partners mostly focused on enabling changes within the TIP's time frame. Both enabling changes and enabling IS/IT were addressed in various ways within the TIP. The lack of head-on tackling of prerequisites outside the TIP's control limited the scope for sustainable business change and indirectly affected the achievement of the intended investment objectives.

For enabling sustainable changes to inter-organisational digitalisation efforts seeking to realise societal, interorganisational and organisational benefits, it is necessary to identify and understand enablers at all three levels. For instance, a wide range of enabling changes at the organisational level has been listed in BMM 
literature including such as training in technical devices and solutions and reallocation of budgets or resources (Ward and Daniel, 2006). Expanding the understanding of enabling changes to the inter-organisational level can be done by including elements which are identified to be essential for collaboration across organisations such as collaboration agreement and governance or infrastructure allowing information to be transferred between different technological solutions. Enabling changes at the societal level can be specified by identifying enabling and constraining conditions beyond the inter-organisational level.

Proposition for overcoming Challenge 4:

4. The identification of necessary enabling changes, including enabling IS/IT at the societal, interorganisational and organisational level is required.

\subsection{Challenge 5: Establishing ownership for enabling changes}

The analysis of the TIP case revealed change owners at two levels: within the TIP and outside the TIP's control. There was uncertainty about the change ownership for enablers within the TIP. This also supports existing BMM literature which proposes to individually name change owners for avoiding uncertainty. In addition to change owners within the TIP, the TIP partners also point to change owners outside the TIP's control (e.g. politicians, government) and link them to enablers outside the TIP's control (e.g. the Norwegian statutory financing system). Following the suggestions of Ward and Daniel (2012) about individually naming change owners from operational services would still be too simple for digitalisation efforts that require changes also at societal and inter-organisational levels. Identifying change owners at multiple layers is needed. Based on the examples of inter-organisational and societal enabling changes given in previous section (challenge 4), an inter-organisational change owner can for instance be individuals pointed to responsible for developing an agreement for inter-organisational collaboration. Further, if allocation of national funding is decisive for sustainable service, the change ownership of this issue is out of organisational or inter-organisational control and requires involvement from specific stakeholders at national level to enable changes- which can be seen as change owners at societal level.

Proposition for overcoming Challenge 5:

5. Change owners at the societal, inter-organisational and organisational levels are required.

Table 4: Summary of challenges and propositions

\begin{tabular}{|l|l|l|}
\hline $\begin{array}{l}\text { BMM literature } \\
\text { key concepts }\end{array}$ & $\begin{array}{l}\text { Challenges of using BMM frameworks } \\
\text { in inter-organisational digitalisation } \\
\text { projects }\end{array}$ & $\begin{array}{l}\text { Propositions to extend the BMM literature to cater } \\
\text { for inter-organisational digitalisation efforts }\end{array}$ \\
\hline Business benefits & $\mathrm{C} 1$ : Formulating the expected benefits & $\begin{array}{l}\mathrm{P}_{1} \text { : The identification of benefits at the societal, inter- } \\
\text { organisational and organisational levels is required to } \\
\text { realise benefits at the societal, inter-organisational } \\
\text { and organisational levels. }\end{array}$ \\
\hline Benefit owner & $\begin{array}{l}\mathrm{C}_{2} \text { : Establishing ownership for expected } \\
\text { benefits }\end{array}$ & $\begin{array}{l}\mathrm{P}_{2} \text { : Benefit owners at the societal, inter-organisational } \\
\text { and organisational levels are necessary to realise } \\
\text { benefits at societal, inter-organisational and } \\
\text { organisational levels. }\end{array}$ \\
\hline Business changes & $\begin{array}{l}\mathrm{C}_{3} \text { : Understanding necessary business } \\
\text { changes }\end{array}$ & $\begin{array}{l}\mathrm{P}_{3} \text { : Identifying necessary business changes at the } \\
\text { societal, inter-organisational and organisational is } \\
\text { required. }\end{array}$ \\
\hline $\begin{array}{l}\text { Enabling changes/ } \\
\text { enabling IS/IT }\end{array}$ & $\mathrm{C}_{4}$ : Understanding enabling changes & $\begin{array}{l}\mathrm{P}_{4}: \text { The identification of necessary enabling changes, } \\
\text { including enabling IS/IT at the societal, inter- } \\
\text { organisational and organisational level is required. }\end{array}$ \\
\hline Change owner & $\begin{array}{l}\mathrm{C}_{5} \text { : Establishing ownership for enabling } \\
\text { changes }\end{array}$ & $\begin{array}{l}\mathrm{P}_{5} \text { : Change owners at the societal, inter-organisational } \\
\text { and organisational levels are required. }\end{array}$ \\
\hline
\end{tabular}

\section{Conclusion}

Existing BMM literature are designed to support BR practices within a single organisation. However, current digitalisation efforts typically involve multiple organisations. We have investigated this gap by exploring BM in a complex case involving many organisations from both the private and the public sector to obtain a thorough understanding of the actual problem. Consequently, we outline five challenges related to realising benefits in complex settings. We also propose five actions that should be seen as a research agenda to facilitate BM in complex settings. Our case is unique (e.g., conducted in a Norwegian health context, includes the specified range of key stakeholders representing multiple levels of public and private organisations, touches the specific structure of the allocation of national funding for healthcare services to municipalities, hospitals and GPs), and the concrete problems encountered are specific to the case. However, the natures of the problems identified, 
connected to the non-optimally aligned distribution of benefits and changes across multiple actors, are more generic and allow us to generalize.

\subsection{Implications for research}

Recent literature emphasises that digitalisation efforts in the public sector are becoming increasingly interorganisational (Gil-Garcia, 2012). Our study has illustrated that the BMM literature is not tailored for this reality. Consequently, more research is needed to develop existing BMM approach to meet current demands or to develop entirely new practices to facilitate the realisation of societal benefits. Our five propositions can be seen as initial and tentative basis for such development.

To further the research on these challenges we recommend three directions for future research. First, in terms of methodology, a powerful approach that could be used to investigate all of these propositions is the comparative method, using qualitative comparative analysis (QCA) (Ragin, 1989; Marx, Rihoux and Ragin, 2014), because it was developed to validate propositions involving necessary conditions (such as those included in the propositions above). While a relatively new method in IS research, there are some good exemplars of the technique (Lapointe and Rivard, 2005). Second, in terms of theory, we recommend that researchers take advantage of multilevel theory (Klein, Dansereau and Hall, 1994), given that all the propositions involve the identification and analysis of levels. While multilevel theory presents longstanding concepts (Kozlowski and Klein, 2000), researchers should also be aware of new ways of theorising levels in organisational and societal settings (Mathieu and Chen, 2011; Burton-Jones and Volkoff, 2017). Third, in terms of topic, researchers should be aware that some of the propositions take the BM field into new topic areas that need to be developed in much more detail. In particular, the literature on BM tends to take an organisational perspective; however, our research has shown that the literature needs to go far beyond this to consider inter-organisational and societal dimensions if digital transformation projects are to achieve their potential.

\subsection{Implications for practice}

Our findings suggest that realising benefits in inter-organisational settings is more challenging than realising benefits within a single organisation. As existing frameworks of BMM are geared towards single organisations, these frameworks currently, at best, offer only limited advice for practitioners.

This study suggests five challenges and five propositions, pointing out issues of importance for BM in interorganisational efforts. Even though we acknowledge the limitation of using a single case study approach, in this case a Norwegian eHealth effort including its variables that of contexts, stakeholders, regulations and structures, the identified challenges provide a useful understanding of potential problems consortia may experience when embarking on joint digitalisation efforts. This understanding can help prepare managers at different levels for what they are likely to experience. Our five propositions include practical advice related to each challenge that managers can consider, hence, avoiding serious problems in their inter-organisational digitalisation efforts.

\section{Acknowledgement}

We would like to express our greatest gratitude to our informants representing the multiple levels of organisations in public and private sector collaborating in the TIP for taking their time and provide us useful insights through interviews, project meetings and workshops. We also would like to thank the Norwegian Research Council for their support (project nr. 247929). Further, we acknowledge Professor Andrew BurtonJones for interesting discussions about the phenomenon of BM in complex digitalisation efforts in general and for novel inputs to this specific paper which in sum has, without doubt, increased the quality of content and outcome of our research, together with the comments received from the Editor and two anonymous reviewers. 


\section{References}

Ashurst, C., Doherty, N. and Peppard, J., 2008. Improving the impact of IT development projects: the benefits realization capability model. European Journal of Information Systems, 17(4), pp.352-370.

Askedal, K., 2019. Understanding the complexity of benefits management in an interorganizational eHealth effort. In proceedings of the 52nd Hawaii International Conference on System Sciences, Maui, HI., 2019.

Badewi, A., 2016. The impact of project management (PM) and benefits management (BM) practices on project success: towards developing a project benefits governance framework. International Journal of Project Management, 34 (4), pp.761-778.

Boonstra, A. and De Vries, J., 2008. Managing stakeholders around inter-organizational systems: a diagnostic approach. The Journal of Strategic Information Systems, 17 (3), pp.190-201.

Burton-Jones, A., Akhlaghpour, S., Ayre, S., Barde, P., Staib, A. and Sullivan, C., Forthcoming. Changing the conversation on evaluating digital transformation in healthcare: insights from an institutional analysis. Information and Organization.

Burton-Jones, A. and Volkoff, O., 2017. How can we develop contextualized theories of effective use? A demonstration in the context of community-care electronic health records. Information Systems Research, 28 (3), pp.468-489.

Chen, W. and Hirschheim, R., 2004. A paradigmatic and methodological examination of information systems research from 1991 to 2001. Information Systems Journal, 14 (3), pp.197-235.

Christensen, J. K. B., 2017. Network dynamics in an interorganizational telemedicine network: a longitudinal qualitative case study of the large-scale TeleCare North Program. PhD. Aalborg University. [online]. Available at: http://vbn.aau.dk/ws/files/260046657/PHD Jannie Kristine Bang Christensen E pdf.pdf [Accessed 03.10.2019].

Coombs, C. R., 2015. When planned IS/IT project benefits are not realized: a study of inhibitors and facilitators to benefits realization. International Journal of Project Management, 33 (2), pp.363-379.

Doherty, N. F., 2014. The role of socio-technical principles in leveraging meaningful benefits from IT investments. Applied Ergonomics, 45 (2), pp.181-187.

Doherty, N. F., Ashurst, C. and Peppard, J., 2012. Factors affecting the successful realisation of benefits from systems development projects: findings from three case studies. Journal of Information Technology, 27 (1), pp.1-16.

Farbey, B., Targett, D. and Land, F., 1994. The great IT benefit hunt. European Management Journal, 12 (3), pp.270-279.

Flak, L., 2012. Gevinstrealisering og offentlige IKT-investeringer: Oslo: Universitetsforlaget AS.

Flak, L. S., Solli-Saether, H. and Straub, D., 2015. Towards a theoretical model for co-realization of IT value in government. In: Proceedings of the 48th Hawaii International Conference on System Sciences, Kauai, HI, 2015.

Flyvbjerg, B., 2006. Five misunderstandings about case-study research. Qualitative Inquiry, 12 (2), pp.219-245.

Frisk, J. E., Bannister, F. and Lindgren, R., 2015. Evaluation of information system investments: a value dials approach to closing the theory-practice gap. Journal of Information Technology, 30 (3), pp.276-292.

Garmann-Johnsen, N. F. and Eikebrokk, T. R., Critical success factors for inter-organizational process collaboration in eHealth. In: proceedings of the Sixth International Conference on eHealth, Telemedicine, and Social Medicine, Barcelona, Spain, 2014.

Ghildyal, A., Chang, E. and Joiner, K., 2018. A survey of benefit approaches and innovation loop required for IT governance. Archives of Business Research, 6 (10), pp.56-77.

Gil-Garcia, J. R., 2012. Towards a smart State? Inter-agency collaboration, information integration, and beyond. Information Polity, $17(3,4)$, pp.269-280.

Hellang, $\varnothing$., Flak, L. S. and Päivärinta, T., 2013. Diverging approaches to benefits realization from public ICT investments: a study of benefits realization methods in Norway. Transforming Government: People, Process and Policy, 7 (1), pp.93108.

Hirschheim, R. and Klein, H. K., 2012. A glorious and not-so-short history of the information systems field. Journal of the Association for Information Systems, 13 (4), pp.188.

Juell-Skielse, G., Lönn, C.-M. and Päivärinta, T., 2017. Modes of collaboration and expected benefits of inter-organizational E-government initiatives: a multi-case study. Government Information Quarterly, 34 (4), pp.578-590.

Klein, K. J., Dansereau, F. and Hall, R. J., 1994. Levels issues in theory development, data collection, and analysis. Academy of Management Review, 19 (2), pp.195-229.

Kozlowski, S. W. and Klein, K. J., 2000. A multilevel approach to theory and research in organizations: Contextual, temporal, and emergent processes. In: Klein, K. J.andKozlowski, S. W. (eds.). 2000. Mulilevel theory, research and methods in organizations: foundations, extensions, and new directions. San Fransisco, CA: Jossey- Bass. pp.3-90.

Lapointe, L. and Rivard, S., 2005. A multilevel model of resistance to information technology implementation. MIS Quarterly, 29 (3), pp.461-486.

Lin, C., Pervan, G. and Mcdermid, D., 2007. Issues and recommendations in evaluating and managing the benefits of public sector IS/IT outsourcing. Information Technology \& People, 20 (2), pp.161-183.

Lönn, C.-M., Juell-Skielse, G. and Päivärinta, T., 2016. Modes of collaboration for realizing e-government benefits. In: proceedings of the 49th Hawaii International Conference on System Science, Kauai, HI, 2016.

Marnewick, C., 2017. The reality of adherence to best practices for information system initiatives. International Journal of Managing Projects in Business, 10 (1), pp.167-184.

Marx, A., Rihoux, B. and Ragin, C., 2014. The origins, development, and application of Qualitative Comparative Analysis: the first 25 years. European Political Science Review, 6 (1), pp.115-142. 
Mathieu, J. E. and Chen, G., 2011. The etiology of the multilevel paradigm in management research. Journal of Management, 37 (2), pp.610-641.

Mitchell, R. K., Agle, B. R. and Wood, D. J., 1997. Toward a theory of stakeholder identification and salience: Defining the principle of who and what really counts. Academy of Management Review, 22 (4), pp.853-886.

Mohan, K., Ahlemann, F. and Braun, J., 2016. Realising value from projects: a performance-based analysis of determinants of successful realisation of project benefits. International Journal of Project Organisation and Management, 8 (1), pp.1-23.

Mueller, B. and Urbach, N., 2017. Understanding the Why, What, and How of theories in IS research. Communications of the Association for Information Systems, 41 (17), pp.349-388.

Orlikowski, W. J. and Baroudi, J. J., 1991. Studying information technology in organizations: research approaches and assumptions. Information Systems Research, 2 (1), pp.1-28.

Peppard, J., Ward, J. and Daniel, E., 2007. Managing the realization of business benefits from IT Investments. MIS Quarterly Executive, 6 (1), pp.1-11.

Ragin, C., 1989. The Comparative Method: moving beyond qualitative and quantitative strategies. [e-book] Berkeley, University of California Press. Available at:

http://search.ebscohost.com/login.aspx?direct=true\&db=nlebk\&AN=306041\&site=ehost-live [Accessed 01.10.2019.].

Remenyi, D. and Sherwood-Smith, M., 1998. Business benefits from information systems through an active benefits realisation programme. International Journal of Project Management, 16 (2), pp.81-98.

Ringard, Å., Sagan, A., Saunes, I. S. and Lindahl, A. K., 2013. Norway: health system review. Health Systems in Transition, 15 (8), pp.1-162.

Seemann, J., Dinesen, B. and Gustafsson, J., 2013. Interorganizational innovation in systemic networks: TELEKAT findings. The Innovation Journal: The Public Sector Innovation Journal, 18 (3), pp.1-18.

Van Fenema, P. C. and Keers, B. M., 2018. Interorganizational performance management: a co-evolutionary model. International Journal of Management Reviews, 20 (3), pp.772-799.

Villumsen, S., Nøhr, C. and Faxvaag, A., 2018. Translating eHealth visions from strategy to practice- a benefit management approach. In: Ugon, A., Karlsson, D., Klein, G. O.andMoen, A. (eds.) Buidling continendts of knowledge in oceans of Data: the future of co-created eHealth. [e-book]. Amsterdam: IOS Press.pp.885-889. Available at: https://doi.org/10.3233/978-1-61499-852-5-885 [Accessed 01.10.2019.].

Walsham, G., 1995. Interpretive case study in IS research. Nature and Method. European Journal of Information Systems, 4, pp.74-81.

Ward, J. and Daniel, E., 2006. Benefits management: delivering value from IS \& IT investments, Chichester: Wiley.

Ward, J. and Daniel, E., 2012. Benefits management: how to increase the business value of your IT projects, West Sussex: John Wiley \& Sons.

Ward, J., Taylor, P. and Bond, P., 1996. Evaluation and realisation of IS/IT benefits: an empirical study of current practice. European Journal of Information Systems, 4 (4), pp.214-225.

Waring, T., Casey, R. and Robson, A., 2018. Benefits realisation from IT-enabled innovation: a capability challenge for NHS English acute hospital trusts? Information Technology \& People, 31 (3), pp.618-645. 